\title{
CONTRIBUTIONS OF THE VULCANO EXPERIMENTAL PROGRAMME TO THE UNDERSTANDING OF MCCI PHENOMENA
}

\author{
CHRISTOPHE JOURNEAU*, PASCAL PILUSO, PATRICIA CORREGGIO, LIONEL FERRY, GÉRALD FRITZ, \\ JEAN FRANÇOIS HAQUET, JOSÉ MONERRIS, JEAN-MICHEL RUGGIERI, MATHIEU SANCHEZ-BRUSSET, \\ and CLEMENTE PARGA \\ CEA, DEN, Cadarache, STRI/LMA, F13108 St Paul lez Durance, France \\ "Corresponding author. E-mail : christophe.journeau@cea.fr
}

Received March 18, 2012

\begin{abstract}
Molten Core Concrete Interaction (MCCI) is a complex process characterized by concrete ablation and volatile generation; Thermal and solutal convection in a bubble-agitated melt; Physico-chemical evolution of the corium pool with a wide solidification range (of the order of $1000 \mathrm{~K}$ ).

Twelve experiments have been carried out in the VULCANO facility with prototypic corium and sustained heating.

The dry oxidic corium tests have contributed to show that silica-rich concrete experience an anisotropic ablation. This unexpected ablation pattern is quite reproducible and can be recalculated, provided an empirical anisotropy factor is assumed. Dry tests with oxide and metal liquid phases have also yielded unexpected results: a larger than expected steel oxidation and unexpected topology of the metallic phase (at the bottom of the cavity and also on the vertical concrete walls). Finally, VULCANO has proved its interest for the study of mitigation solutions such as the COMET bottom flooding core catcher.
\end{abstract}

KEYWORDS : Severe Accidents, Corium, Concrete, Basemat, Ablation, Metal, Core Catcher

\section{INTRODUCTION}

In the case of a severe accident with a nuclear reactor, the core could melt and form a molten pool called corium. It could eventually melt through the vessel and interact with the pit concrete. Corium is thus composed of uranium oxide, partly or totally oxidized zirconium, steel and its oxides, fission products, which mixed with decomposed concrete in the reactor pit. In current LWRs, this concrete basemat is the ultimate barrier, while in the EPR [1], the reactor pit provides temporary melt retention before spreading in the core catcher. Calculations of the Fukushima Dai-ichi accident at the time of writing suggest [2] that vessels from units 1-3 have failed and that corium has interacted with the concrete.

Molten Core Concrete Interaction (MCCI) is a complex process characterized by concrete ablation and volatile generation; Thermal and solutal convection in a bubbleagitated melt; Physico-chemical evolution of the corium pool with a wide solidification range (of the order of $1000 \mathrm{~K}$ ).

Experiments on MCCI started in the 1980s [3]. Although numerous Molten Core Concrete Interaction experiments have already been performed, there were still large uncertainties mainly on the two-dimensional profiles of the ablation velocity and on the effect of the metallic layer. These issues have thus been classified with a high priority by the SARNET Severe Accident Research Priorities Group [4]. A recent review on state of the art MCCI can be found in Reference [5].

The VULCANO facility [6] is dedicated to the study of corium behaviour at a medium scale $(30-70 \mathrm{~kg})$. It is complementary to the larger scale CCI facility [7]. Indeed, the differences in shape, size and heating technique is a way to prevent system effects. Moreover, VULCANO can deal with a large metallic phase while providing the heat to the oxidic phase.

In the first section, the facility will be described, then the results from the experimental series dealing with dry 2D MCCI with pure oxidic coriums [8], dry 2D MCCI with oxides and metals and MCCI with water flooding will be presented.

\section{FACILITY DESCRIPTION}

VULCANO $[6,9]$ is a facility mainly consisting of furnaces for oxides and metals, as well as test sections, which can be adapted to the specificity of each experiment. It is currently devoted to a Molten Core Concrete Interaction experimental program. 


\subsection{The VULCANO Furnace}

Up to $100 \mathrm{~kg}$ of oxidic mixtures of various compositions [in-vessel corium $\left(\mathrm{UO}_{2}-\mathrm{ZrO}_{2}, \mathrm{Fe}\right)$, ex-vessel corium (invessel + concrete decomposition products: $\mathrm{SiO}_{2}, \mathrm{CaO}, \mathrm{FeOx}$, $\left.\mathrm{Al}_{2} \mathrm{O}_{3}, \mathrm{MgO}, \ldots\right)$ ] can be melted in the VULCANO plasmaarc rotating furnace [10] shown in Fig. 1.

The mixtures to be melted are inserted as powders in a cylindrical rotating cavity $(400 \mathrm{~mm}$ diameter $-500 \mathrm{~mm}$ long) and centrifugation (between 150 and $300 \mathrm{rpm}$ ) coats these mixtures against the furnace wall. In the first phase, zirconia powder is loaded to form by heating a self crucible, then, the corium constituents are loaded in the furnace as powders.

Two graphite plasma torches are ignited and the main arc is then created and transferred between these two torches. At the end of the melting phase, the anode is withdrawn, the furnace is tilted: the melted mixture pours out and an inclined plane leads it to the test section.

Two corium load compositions have been used in the VULCANO MCCI (VB) test matrix (Table I). It must be noted that the composition is modified during the melting process (dilution of the zirconia self-crucible, volatilization of some silicon and iron).

\subsection{Concrete Test Sections}

Concrete is a complex material made of cement, water and aggregates. These aggregates are divided into sand and gravel, depending on their size with a threshold value of a few millimetres. Mortar is defined as a mixture of cement, water and sand.

The test sections (Fig. 2) are $600 \times 300 \times 400 \mathrm{~mm}$ concrete blocks with a $\varnothing 300 \times 250 \mathrm{~mm}$ hemicylindrical cavity (area $\sim 350 \mathrm{~cm}^{2}$, volume $\sim 9 \mathrm{~L}$ ) in which corium is poured. Several types of concrete have been studied (Table II), either representative of nuclear reactor basemats or specially designed to study one character of concrete. Concrete $\mathrm{F}$ and $\mathrm{G}$ represent respectively a silica-rich and a limestone-rich concrete, typical of several power plants. Concrete E represents the ferro-siliceous sacrificial

Table I. VULCANO MCCI Program Corium Load Compositions

\begin{tabular}{c|c|c|c|c|c}
\hline $\mathbf{W t} \%$ & $\mathrm{UO}_{2}$ & $\mathrm{ZrO}_{2}$ & $\mathbf{S i O}_{2}$ & $\mathbf{F e}_{2} \mathbf{O}_{3}$ & $\mathbf{C a O}$ \\
\hline Corium 1 & 45 & 19 & 20 & 15 & - \\
\hline Corium 2 & 69 & 17 & 6 & 7 & 1 \\
\hline
\end{tabular}

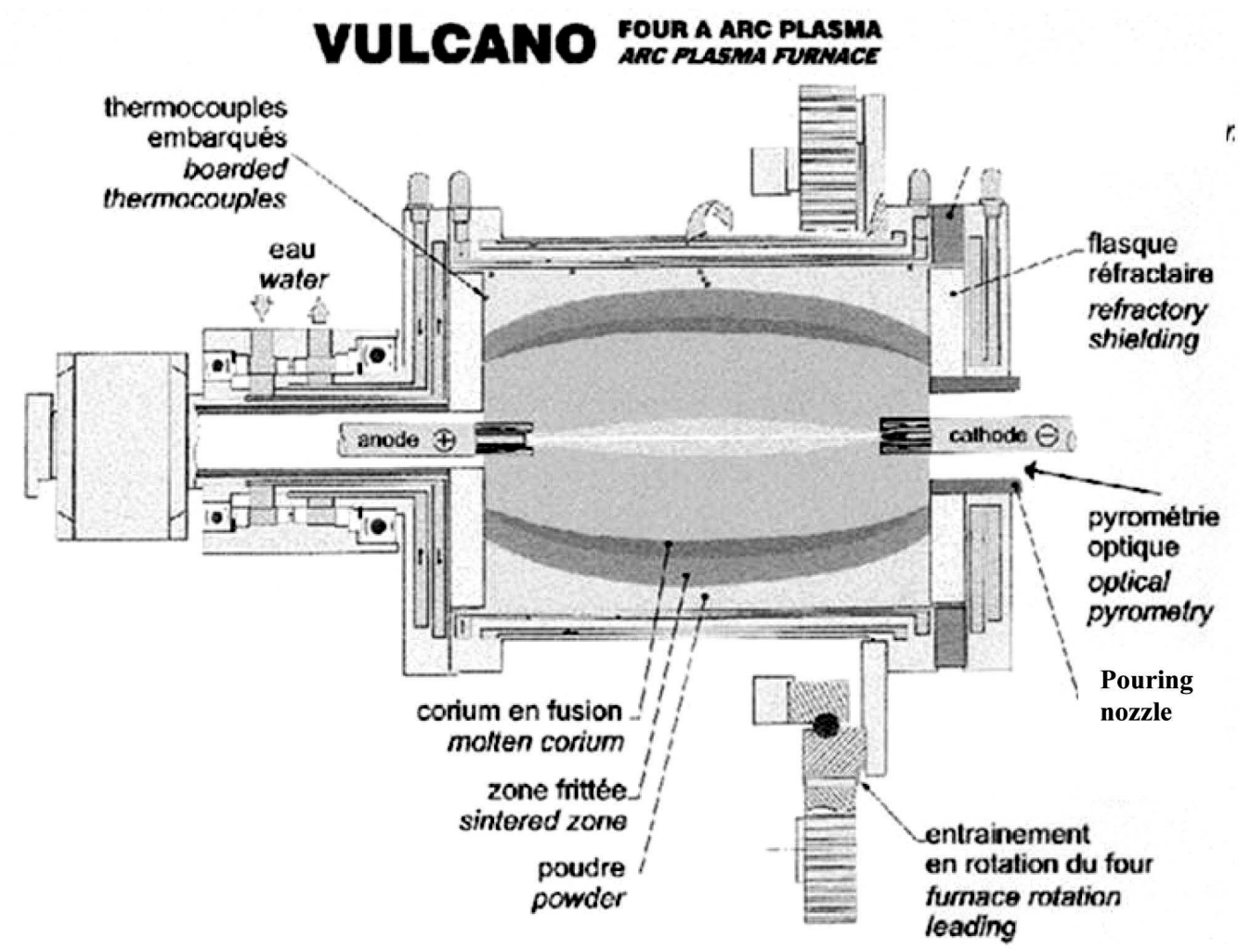

Fig. 1. The VULCANO Plasma arc Rotating Furnace 
concrete from EPR Olkiluoto [11]. Concrete $\mathrm{C}$ is a specific formulation using clinker (calcinated limestone) aggregates in order to have a composition close to that of Concrete $\mathrm{G}$, but without carbon dioxide. Mortar $\mathrm{F}$ is a mortar having a close composition to Concrete $\mathrm{F}$ but containing no gravel.

More than $100 \mathrm{~K}$-type thermocouples are installed in the test section before concrete has been poured. They are mainly used to monitor the concrete ablation. Some high temperature C-type thermocouples are also installed to monitor the molten pool temperature.

Four parallel induction coils surround the section and provide sustained heating (Figure 2). Free (unconnected) coils are also installed below the induction coil, to provide electromagnetic shielding to the lower part (where the metallic layer is supposed to be segregated) as well as water cooling. During the test, induction provides heating power to the corium pool. A part of this heat is lost by conduction through the refractory wall closing the cavity and measured thanks to heat balanced measurement in the water-cooled coils (deducing the ohmic power in the coils). We define net power as the difference between the injected power and the conductive losses. This net power contributes to concrete ablation and heating, as well as radiation at the corium free surface, neglecting chemical interaction heat.

The test sections are installed in the VULCANO containment and operate in air at atmospheric pressure.

\section{THE 2D DRY OXIDIC CORIUM TESTS}

Six experiments (Table III) have been carried out, at the time of writing, with purely oxidic corium and 2D (hemi-cylindrical) geometry, in parallel to the CCI program at Argonne National Laboratory (in a rectangular geometry) [7]. The first 4 tests (VB-U4, U5, U6, and U7) correspond to typical power plant concrete while the last two (VBES$\mathrm{U} 2$ and VBES-U3) correspond to specific compositions.
Oxide
furnace

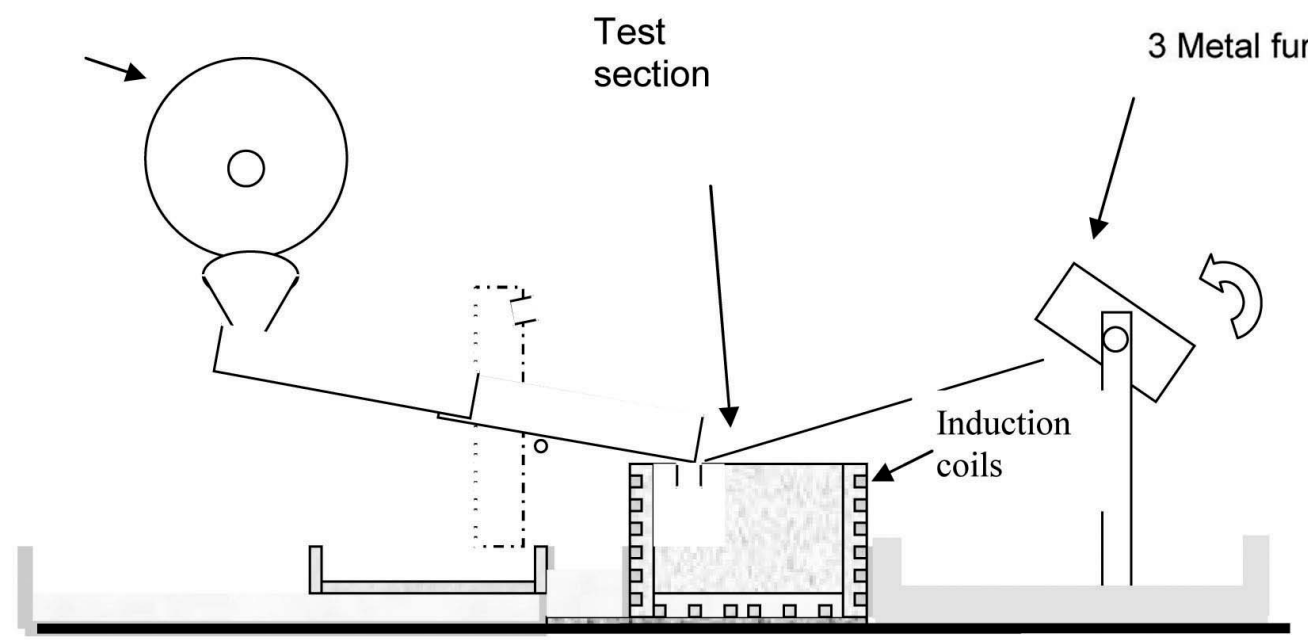

Fig. 2. Scheme of the VULCANO Facility with 2 Furnaces and Test Section

Table II. Chemical Composition of the Dried Concretes used in the VULCANO Tests

\begin{tabular}{c|c|c|c|c|c|c|c}
\hline wt $\%$ & $\mathrm{CaO}$ & $\mathrm{CO}_{2}$ & $\mathrm{SiO}_{2}$ & $\mathrm{Al}_{2} \mathrm{O}_{3}$ & $\mathrm{Fe}_{2} \mathrm{O}_{3}$ & $\mathrm{MgO}$ & $\mathrm{H}_{2} \mathrm{O}$ \\
\hline "Concrete C" & 49.2 & - & 29.6 & 3.9 & 2.1 & 0.9 & 10.7 \\
\hline "Concrete E" & 12.7 & 1.4 & 45.5 & 3.3 & 32.9 & 0.3 & 3.7 \\
\hline "Concrete F" & 16 & 9 & 63 & 5 & - & - & 3 \\
\hline "Mortar F" & 18 & 7 & 58 & 5 & 1 & 0.5 & 7.5 \\
\hline "Concrete G" & 42 & 25 & 26 & 2 & - & - & 4 \\
\hline
\end{tabular}


Table III. VULCANO 2D Oxidic MCCI Experimental Matrix

\begin{tabular}{c|c|c|c|c|c|c}
\hline Test & VB-U4 & VB-U5 & VB-U6 & VB-U7 & VBES-U2 & VBES-U3 \\
\hline Concrete & Concrete F & Concrete F & Concrete G & Concrete E & Concrete C & Mortar F \\
\hline Initial mass & $45 \mathrm{~kg}$ & $28 \mathrm{~kg}$ & $31 \mathrm{~kg}$ & $54 \mathrm{~kg}$ & $45 \mathrm{~kg}$ & $29 \mathrm{~kg}$ \\
\hline Initial temperature & $\sim 2200 \mathrm{~K}$ & $\sim 2400 \mathrm{~K}$ & $\sim 2400 \mathrm{~K}$ & $\sim 2500 \mathrm{~K}$ & $\sim 2500 \mathrm{~K}$ & $\sim 2500 \mathrm{~K}$ \\
\hline Average net power & $14 \mathrm{~kW}$ & $12.5 \mathrm{~kW}$ & $9 \mathrm{~kW}$ & $22 \mathrm{~kW}$ & $15 \mathrm{~kW}$ & $9,4 \mathrm{~kW}$ \\
\hline Heating duration & $1 \mathrm{~h} 40$ & $2 \mathrm{~h} 30$ & $2 \mathrm{~h}$ & $2 \mathrm{~h} 40$ & $3 \mathrm{~h}$ & $2 \mathrm{~h} 40$ \\
\hline Ablation tendency & anisotropic & anisotropic & Rather isotropic & anisotropic & anisotropic & Small ablation \\
\hline
\end{tabular}

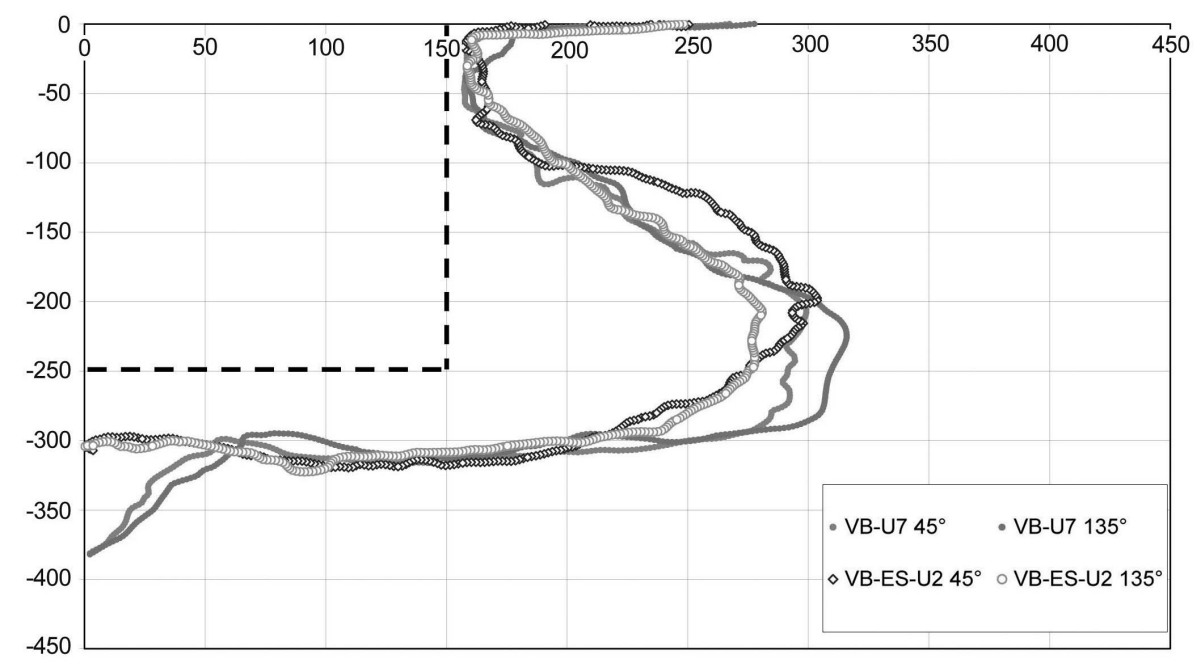

Fig. 3. Post-test Estimation of the Ablation Shapes for VB-U7 and VBES-U2 Experiments

In these tests 28 to $55 \mathrm{~kg}$ of prototypic oxidic corium (corresponding to $16-25 \mathrm{~cm}$ collapsed heights ${ }^{\dagger}$ ) have been poured in the test section cavity. Then the induction heating is switched on for several hours ${ }^{*}$ to simulate the decay heat and observe the concrete ablation.

Before the start of these two experimental programs, it was generally assumed that the concrete ablation, controlled by the convective heat flux due to gas sparging, would be progressing roughly at the same rate in the vertical and horizontal directions ("isotropic ablation behaviour"). Both the CCI and VULCANO programs have shown that silica-rich concretes exhibit anisotropic ablation behaviour: Concrete ablation is significantly more important towards the sidewalls than towards the bottom. For instance, Figure 3 presents the measured final ablation shapes measured by laser telemetry after that the cold corium has been removed from the concrete cavity for experiments VB-U7 and VBES-U2, with concretes E and $\mathrm{C}$, respectively [11]. These two experiments yielded similarly anisotropic final cavity shape after the test has been stopped.

In tests with Concretes F, E and C, the ablation started

\footnotetext{
† If crusts of up to $3 \mathrm{~cm}$ thickness are considered at the bottom and top interfaces, this leaves $10-20 \mathrm{~cm}$ for the liquid corium pool, i.e. $2-3$ times less than in the CCI tests.

* In the latest tests, short periodic induction switch-off, switch-on have been carried out to allow measurements without electromagnetic interferences.
} 


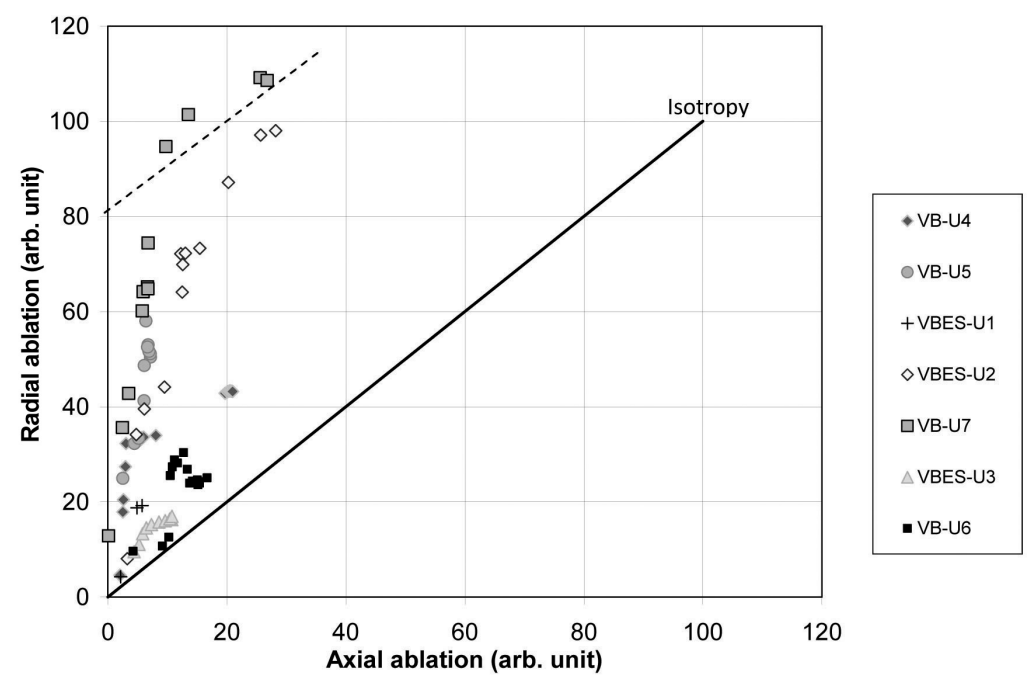

Fig. 4. Experimentally Observed Axial/Radial Ablations during the 7 Tests Defined in Table III

with a large anisotropy (with a ratio between 2 and 3 between radial and axial ablation). In the long term, the ablation ratio tended to decrease. On the opposite, tests with limestone-rich concretes (VB-U6 and CCI-2 [7]) exhibit an isotropic ablation tendency (VB-U6 ablation is not as isotropic as CCI-2, but is nevertheless significantly less anisotropic than the other tests in the VB series. A confirmatory test is under preparation with a limestone-rich concrete). Figure 4 plots the radial and axial ablations estimated (from the relevant interpolated concrete temperature maps) during the 7 oxidic corium 2D ablation experiments at the instant when each thermocouple that has been reached ruptured. Except for tests VB-U6 and VB-ES-U3, all the tests present a significantly more pronounced radial ablation compared to the axial (vertical) ablation. This anisotropy seems to diminish in the longer term (i.e. for larger ablation distances)

The presence of two experimental facilities (VULCANO and CCI) operating at two different scales $(50-1000 \mathrm{~kg})$, with different geometries and heating technique (induction vs. direct current heating) has been a key factor in showing that the risk of experimental artefact was small.

A benchmark exercise [12] conducted on VB-U5 and VB-U6 experiments concluded that, provided the anisotropy ratio is assumed, most codes are able to more or less predict the ablation profile. It must be reminded that current MCCI codes are based on OD quasi steady state models which cannot perfectly reproduce the complexity of MCCI processes. Nevertheless, it has been found necessary to understand the physical causes of the observed anisotropy/isotropy in concrete ablation. Separate effect tests with prototypic corium and specially designed concretes are underway to determine which property of
Table IV. Concentration of Volatile Species in VULCANO Concretes

\begin{tabular}{c|c|c|c|c}
\hline Test & VB-U5 & VB-U7 & VBES-U2 & VB-U6 \\
\hline Concrete & F & $\mathbf{E}$ & $\mathbf{C}$ & $\mathbf{G}$ \\
\hline $\begin{array}{c}\text { Volatile quantity } \\
\left.(\mathrm{kmol} \text { gas/m })^{3}\right)\end{array}$ & 8 & 6 & $\begin{array}{c}14 \\
\left(\mathrm{H}_{2} \mathrm{O}\right)\end{array}$ & $\begin{array}{c}18 \\
\left(\mathrm{CO}_{2}\right)\end{array}$ \\
\hline $\begin{array}{c}\text { Volatile mass fraction } \\
(\mathrm{wt} \%)\end{array}$ & 5 & 12 & 11 & 31 \\
\hline
\end{tabular}

the concrete causes the transition from anistropic to isotropic ablation behaviour $[6,13]$.

Concrete $\mathrm{C}$ has been designed so that it has in molten state a similar composition to concrete $\mathrm{G}$ but without carbonates: the limestone has been replaced by cement clinker (in which carbon dioxide has been removed by calcination). Mortar F has been designed to have the same composition as concrete F but without any gravel. It has some of the properties of limestone concrete where above the decarbonation temperature (around $1000 \mathrm{~K}$ ) no gravel remains. Unfortunately only little ablation was obtained during this test, which is thus hard to interpret.

The following are the provisional results of this test series::

- The gas superficial velocity (gas volume flow rate) does not seem to be the prime cause of the change of behaviour between the two types of concrete ablation. At identical ablation rate, superficial velocity only depends on the quantity of gas generated by a unit volume of ablated concrete (Table IV). It is unlikely 
that there is a sharp transition between concretes $\mathrm{C}$ and G. Small scale simulant material experiments [14] indicate that the transition between highly anisotropic natural convection and more isotropic forced convection occurs at quite low gas superficial velocities, below those estimated for all VULCANO tests.

- There is a significant difference in mass flow rates (which is the product of the ablation rate by the volatile mass fraction - cf. Table IV) between the tests presenting an anisotropic ablation and test VB-U6 with concrete $\mathrm{G}$, due to the different molar masses of steam and carbon dioxide. It must nevertheless be reminded that the models used to describe the convection induced by gas sparging $[15,16]$ are currently based on the volume flow rate (superficial velocity) and not the mass flow rate.

- The molten concrete composition (affecting its liquidus temperature, viscosity, chemical diffusion, ability to dissolve corium crusts [17]) is not the major cause of anisotropy/isotropy, since, although molten concretes $\mathrm{C}$ and $\mathrm{G}$ have almost the same compositions, VB-ESU2 exhibited a clearly anisotropic ablation, as opposed to VB-U6.

- Post test examinations have shown that silica gravel can remain unmelted in the corium pool (Figure 5 left). A similar observation has been made on the clinker gravel in VBES-U2 (Figure 5 right). On the other hand, limestone is destroyed by decarbonation around $1000 \mathrm{~K}$ and forms a fine lime powder which rapidly dissolves in the corium pool of VB-U6. Moreover, quantitative material analyses of tests VB-U4 and VB-U6 have showed that the pool composition was depleted in silica as if the larger gravel had not mixed with the corium while the finer mortar did [8]. The presence of unmelted siliceous gravel may affect the corium behaviour. This was the reason for performing a test VBES-U3 with siliceous mortar F. Unfortunately, this rapidly led to a significant enrichment in silica of the pool and a decrease in its electrical conductivity which is though to have prevented satisfactory long term heating for this test.

- Post test micrographs of the corium pool have shown (see e.g. Figure 6) that there is solutal convection inside the corium pool with plumes of concrete-rich and concrete-poor liquids, which are seen with a very thin spatial separation. Solutal convection is currently not considered in MCCI models [5].

All the tests (both in CCI and VULCANO) start with a transient in which hot corium is put into contact with cold concrete, leading to a rapid crust formation. As neither decay heat nor zirconium oxidation heat is simulated in

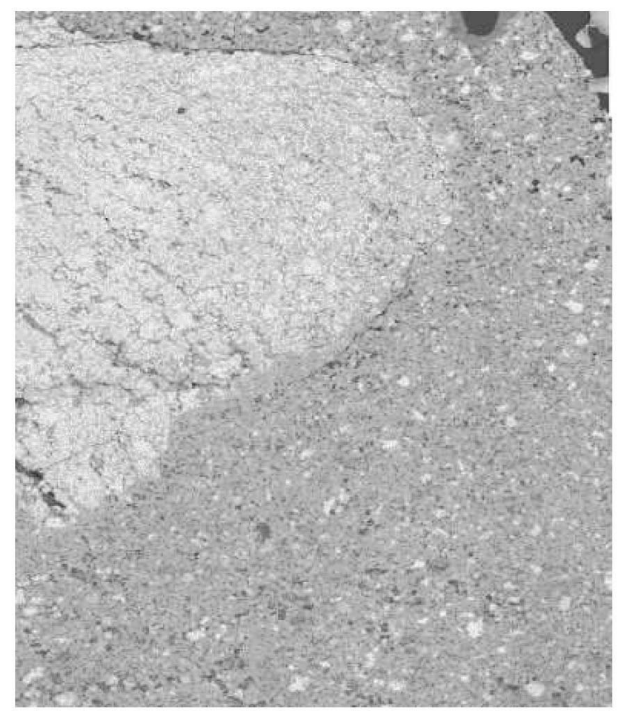

Fig. 6. Composite SEM Micrograph from VB-ESU2 (Lower Part of the Melt Bulk) Corresponding to Slightly More than One $\mathrm{cm}^{2}$. The Clear Zone is Rich in Corium and Poor in Concrete Elements. The Dark Zone is Concrete-rich, but Corium-poor.
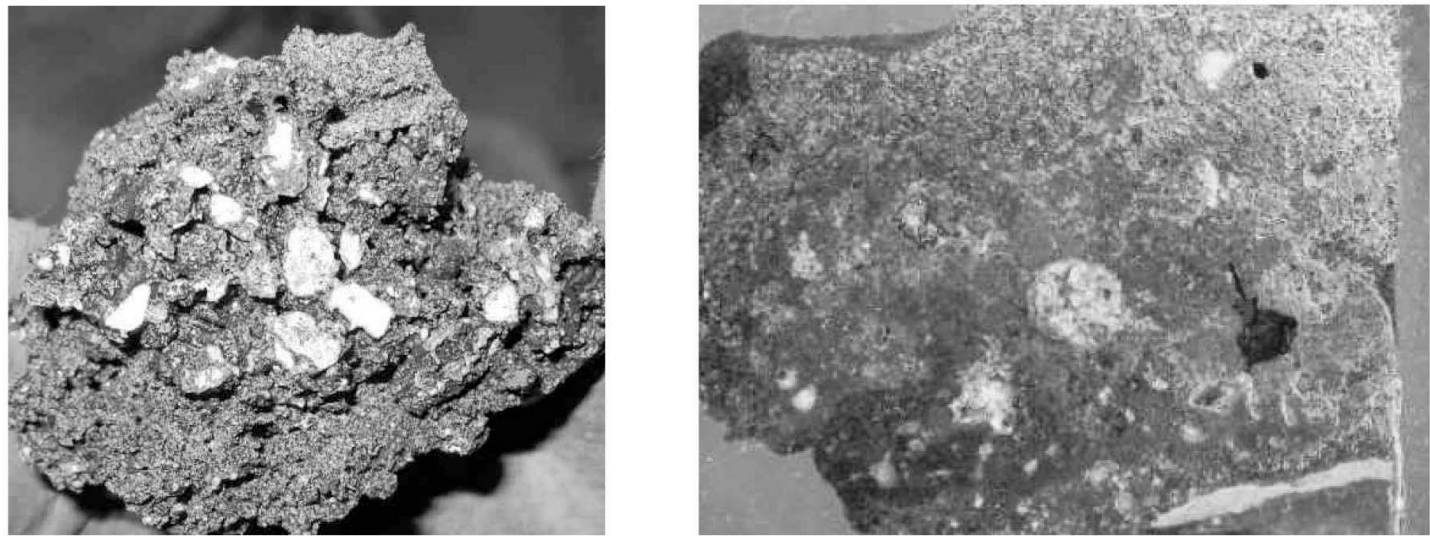

Fig. 5. Corium Samples from VB-U7 (Left) and VBES-U2 (Right) Showing Inclusions of Unmolten Gravel 
our experiments, it takes a very long time for these crusts to melt again, especially for the mechanically stable lower crust over a siliceous material - due to the loss of volume at decarbonation, limestone concrete would provide a less stable support for the bottom crust. In the recent MOCKA simulant tests in which zirconium was introduced [18] axial ablation was found to be more important. Therefore, it is planned to perform a future experiment taking into account the zirconium oxidation heat to verify whether this transient is or not a major cause of the observed anisotropy.

At the time of writing, it is possible to reproduce with TOLBIAC ICB [19] the experimental database assuming a fixed anisotropy ratio of 2 for silica-rich concretes and of 1 (except for an initial transient) for limestone rich concretes. Since a satisfying phenomenological explanation of the anisotropy/isotropy of concrete ablation has yet to be found, it is hard to guarantee the scaling to a reactor pit with a diameter of several meters.-.

\section{THE 2D OXIDE + METAL TESTS}

Before the start of the VULCANO oxide+metal MCCI programme (VBS tests), the following academic configurations were assumed [20]:

- Well-mixed emulsion of metal liquid droplets in an oxidic pool ;

- Gravitational stratification with metal at the bottom and corium-concrete oxides above.

Correlations, like that from the BALISE experiments [21] are used to determine whether the gas sparging is sufficient or not to mix the phases.

Four VULCANO VBS tests have been carried out: one with the limestone-rich concrete $G$, three with the silica-rich concrete F (Table V). Experiment VBS-U2 was repeated due to a bad induction coupling.

During these tests, the oxidic melt is first poured in the cavity. Then 2 to 3 one-litre steel furnaces are poured in the test section cavity. After the pouring sequence, the decay heat simulation is switched on.

\subsection{VBS-U1 with Limestone Rich Concrete}

The most surprising result from the VBS-U1 test [22] was the fact that on a stainless steel initial mass of $15 \mathrm{~kg}$, only $1.5 \mathrm{~kg}$ remained as metallic bodies. Pre test calculations gave an iron oxidation rate of $4 \% / \mathrm{hr}$ [22]. In order to calculate the observed oxidation rate, it has been necessary to take the exaggerated hypothesis that all the oxidizing

Table V. VULCANO Oxidic-metal Experimental Matrix

\begin{tabular}{c|c|c|c}
\hline Test & VBS-U1 & VBS-U2 & VBS-U3 \\
\hline Concrete & Concrete G & Concrete F & Concrete F \\
\hline Oxide Load & Corium 2 & Corium 2 & Corium 2 \\
\hline Initial mass of oxides & $35 \mathrm{~kg}$ & $18 \mathrm{~kg}$ & $36 \mathrm{~kg}$ \\
\hline Initial mass of stainless steel & $15 \mathrm{~kg}$ & $17 \mathrm{~kg}$ & $35 \mathrm{~kg}$ \\
\hline Heating duration & $4 \mathrm{~h}$ & Bad coupling & $24 \mathrm{~kg}$ \\
\hline
\end{tabular}
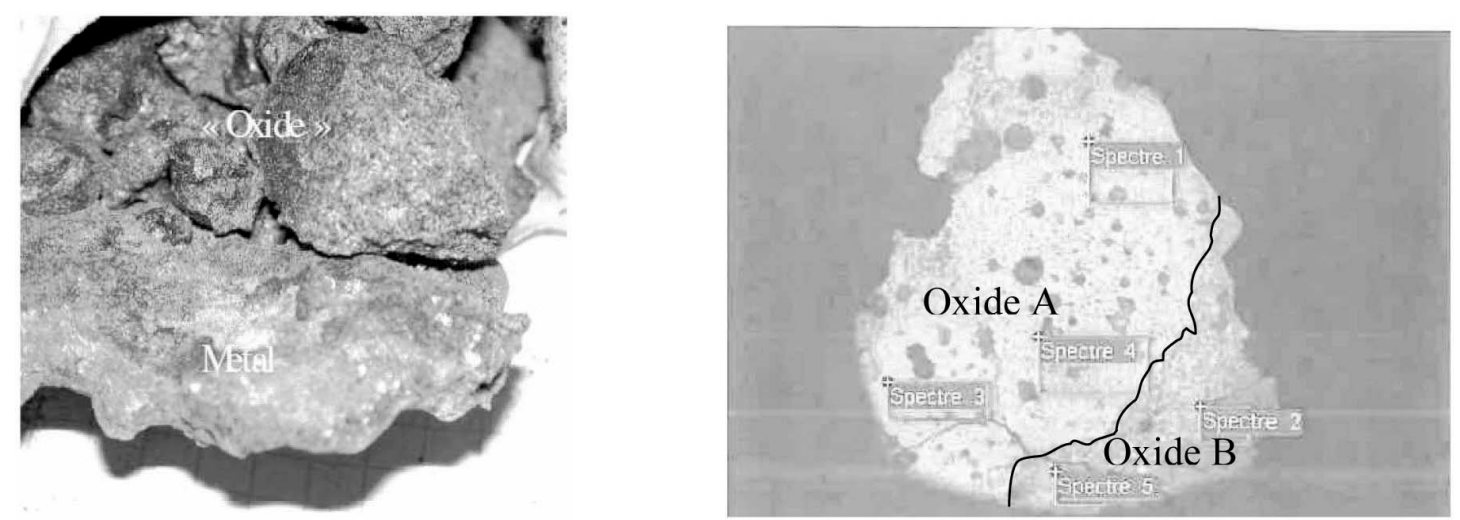

Fig. 7. Metallic Sample for VBS-U1 Below an Oxidic Corium Sample (Left) - Composite SEM Micrograph from the Oxidic Sample (Right) [Image Width $\sim 15 \mathrm{~mm}$ ] 

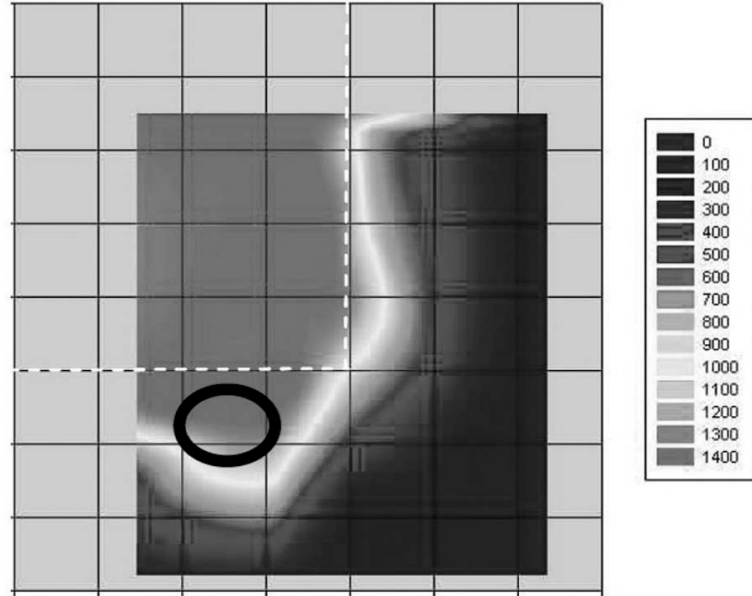

Fig. 8. Experimental Concrete Temperature Field at the $135^{\circ}$ Azimuth at the end of the VBS-U1 Test, the

Dashed Lines show the Original Cavity; the Circle shows the area of Figure 7 Samples. gases not only from the ablated concrete but also from all the regions with a temperature above $100^{\circ} \mathrm{C}^{\S}$ have interacted with the metal, which was found at the deepest area of the cavity. The remaining metal has been totally depleted in $\mathrm{Cr}$ and significantly enriched in $\mathrm{Ni}$ (i.e. depleted in $\mathrm{Fe}$ ) as shown in Table VI. Zones in the oxidic corium have been enriched in concrete materials $\left(\mathrm{CaO}, \mathrm{SiO}_{2}\right)$ and steel oxides $\left(\mathrm{FeO}, \mathrm{Cr}_{2} \mathrm{O}_{3}\right)$.

The complex mechanisms of steel oxidations during MCCI are currently under analysis at CEA.

\subsection{Oxide-metal Tests with Siliceous Concrete}

In the tests with silica-rich concrete $\mathrm{F}$, oxidation of the steel has also been observed but to a smaller extent. As in VBS-U1, the remaining steel was depleted in chromium and enriched in nickel.

The most surprising result from the three tests with concrete $\mathrm{G}$ is the fact that, although a spatial segregation between large metal and oxide phases occurred, this segregation was not gravity stratification with a horizontal interface. For instance, Figure 9 left shows the metallic

Table VI. VBS-U1 Compositions (wt\%) Determined from SEM/EDX Analyses

\begin{tabular}{c|c|c|c|c|c|c|c|c}
\hline wt\% & $\mathrm{Fe}$ & $\mathrm{Cr}$ & $\mathrm{Ni}$ & $\mathrm{U}$ & $\mathrm{Zr}$ & $\mathrm{Ca}$ & $\mathrm{Si}$ & $\mathrm{O}$ \\
\hline Initial Stainless Steel & $69.6 \%$ & $18.2 \%$ & $9.2 \%$ & & & & & \\
\hline Metallic sample (Figure 7) & $49 \%$ & $44 \%$ & - & & & & & \\
\hline Oxide sample (Figure 7) Oxide A zone & $3 \%$ & $1 \%$ & - & $47 \%$ & $17 \%$ & $4 \%$ & $3 \%$ & $25 \%$ \\
\hline Oxide sample (Figure 7) Oxide B zone & $13 \%$ & $5 \%$ & - & $15 \%$ & $5 \%$ & $16 \%$ & $9 \%$ & $37 \%$ \\
\hline
\end{tabular}

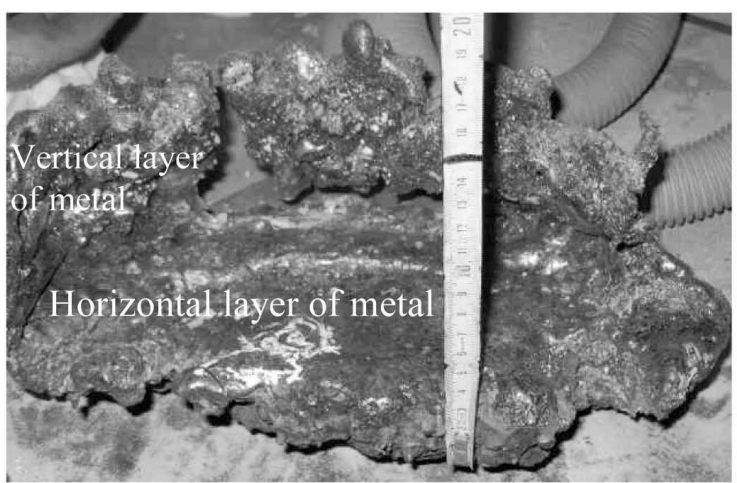

Left: VBS-U4 large metal block

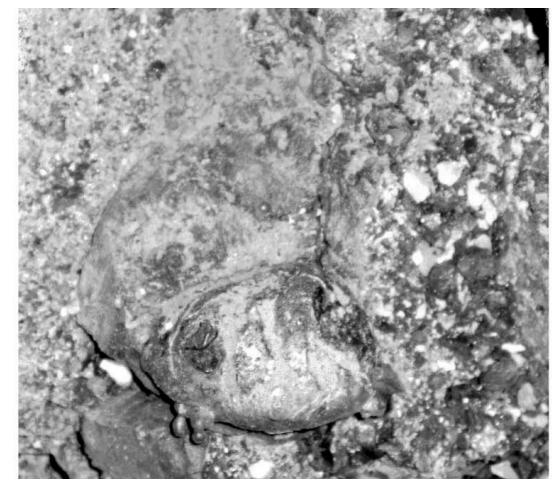

Right: VBS-U3 centimetric drop

Fig. 9. Metallic Phases from MCCI Tests

\footnotetext{
${ }^{\S}$ Experimentally, it has been found that the concrete cold face are wet after tests, showing that a part of the steam flows through the concrete cracks to the cold side and not towards the corium pool.
} 
phase that was extracted from the bottom of the VBS-U4 test section. A part of the metal forms a lower horizontal layer but there are also vertical layers which are adjacent to the concrete hemicylindrical wall (No vertical metallic layer was found on the ceramic wall closing the halfcylinder cavity). Metallic drops have also been observed in the corium pools with sizes from several centimetres down to a tenth of a millimetre. Similar configurations have been observed in the two other tests. In some tests the vertical layer concerned most of the cavity height while in others it was limited to $12 \mathrm{~cm}$. Oxidic melt and unmolten gravel are trapped in some part of the metallic layer.

During the VBS-U3 experiment the vertical and horizontal layer of metal did not cover the entire concrete wall but only an angular sector of slightly less than $90^{\circ}$. Online, temperature concrete measurement showed that axial and radial ablation was more pronounced in the areas where metal has been found post test than in the area where oxidic corium and concrete where facing each other. This is consistent with the analytic experiments that have shown an important heat transfer at the (horizontal) oxide-metal interface.

It must be noted that test VBS-U3 and VBS-U4 have been performed with different corium load compositions. Composition 1 is less dense than composition 2 due to a larger concrete content. This implies that the observed unexpected topology of the metallic phase is not due to a special ratio between oxidic and metallic melt densities.

Due to the ongoing solutal convection, plumes of various concrete fractions - and thus of different densities - are present below the metallic drop. For instance, Figure 10 presents a macrograph of an oxide sample just below the large metallic drop in Figure 9 left. The densities at

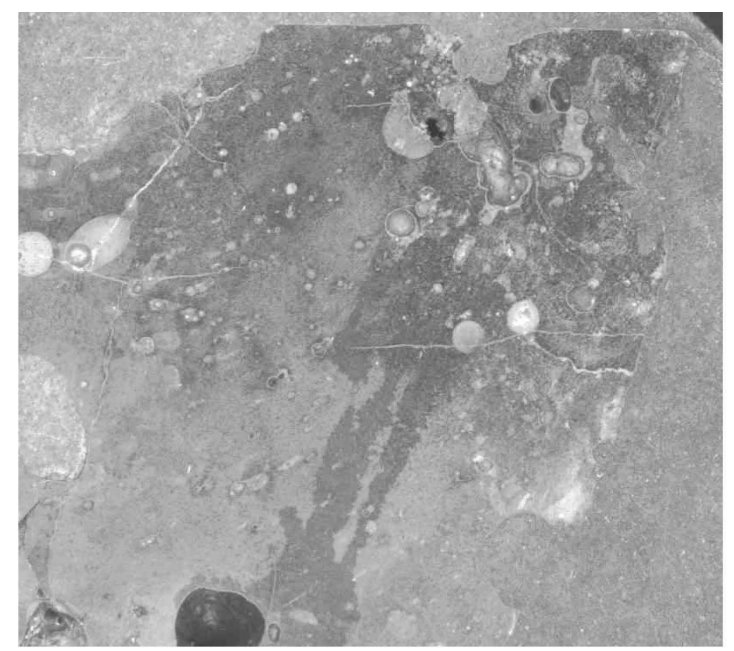

Fig. 10. Macrograph of an Oxide Sample Just Below the Metallic Drop in Figure 9 Left the pool temperature are estimated to $6.2 \mathrm{~kg} / \mathrm{L}$ for the metal, $6.6 \mathrm{~kg} / \mathrm{L}$ for the concrete-poor oxide (in light gray in Figure 10) and $4.6 \mathrm{~kg} / \mathrm{L}$ for the (drak-gray) concrete-rich plume. This shows that the phenomena are far more complex that those represented in simulant material stratification experiments [20] where only two liquid compositions are present. During MCCI, miscible but yet unmixed oxides are present and coexist with immiscible metallic liquid.

The 4 oxide-metal tests performed at the VULCANO facility are the first significant scale experiments with prototypic corium, metal and decay heat simulation in the oxides. In other experiments as COTELS [23], the heat was injected to the metallic phase, due to other characteristics of their induction system.

The VULCANO VBS tests have shown unexpected results regarding the metal oxidation during MCCI and the phase repartition that must be better understood, in order to determine how they can or not be present at a reactor scale.

\section{COOLABILITY TEST}

The VW-U1 test has been carried out to qualify with prototypic corium and sustained heating the COMET PCA concept developed by FZK.[24, 25]. In this core-catcher design, a porous concrete layer is connected to a water tank providing hydrostatic head. Water is maintained in the porous concrete by a leak-tightness concrete layer. If corium arrives on the core catcher, it will ablate the concrete and water from the porous concrete would flow through corium and ensure its coolability.

A 25-cm diameter COMET PCA core catcher (Figure 11) has been installed in a cylindrical zirconia crucible. A steam circuit leading to a condenser has been installed.

After the 20-mm thick sacrificial concrete layer has been ablated in about 3 minutes, the water flow rate reaches a value of 4.5 litres per min, or $75 \mathrm{~g} / \mathrm{s}$. The gas temperature in the upper test vessel land in the off-gas line increased to values in the order of $500^{\circ} \mathrm{C}$ with peaks in the order of $800-1200^{\circ} \mathrm{C}$

The off-gas flow rate was measured by a Pitot tube and by a turbine flowmeter The extracted heat flux, estimated from the steam flow and the enthalpy difference between the steam temperature and the water inlet temperature, reaches a typical value of $75 \mathrm{~kW}$ in the early quenching phase until about $5 \mathrm{~min}$ (Figure 12). This is much higher than the induction heating power (between 10 and $20 \mathrm{~kW}$ corresponding to prototypic heat fluxes of $100-200 \mathrm{~kW} / \mathrm{m}^{2}$ ). After 20 minutes, most of the corium was solidified, boiling liquid water covered the corium and the test was successfully terminated.

The COMET PCA core catcher concept has been satisfactorily validated with prototypic corium and sustained heating in the VULCANO facility. After a short corium- 


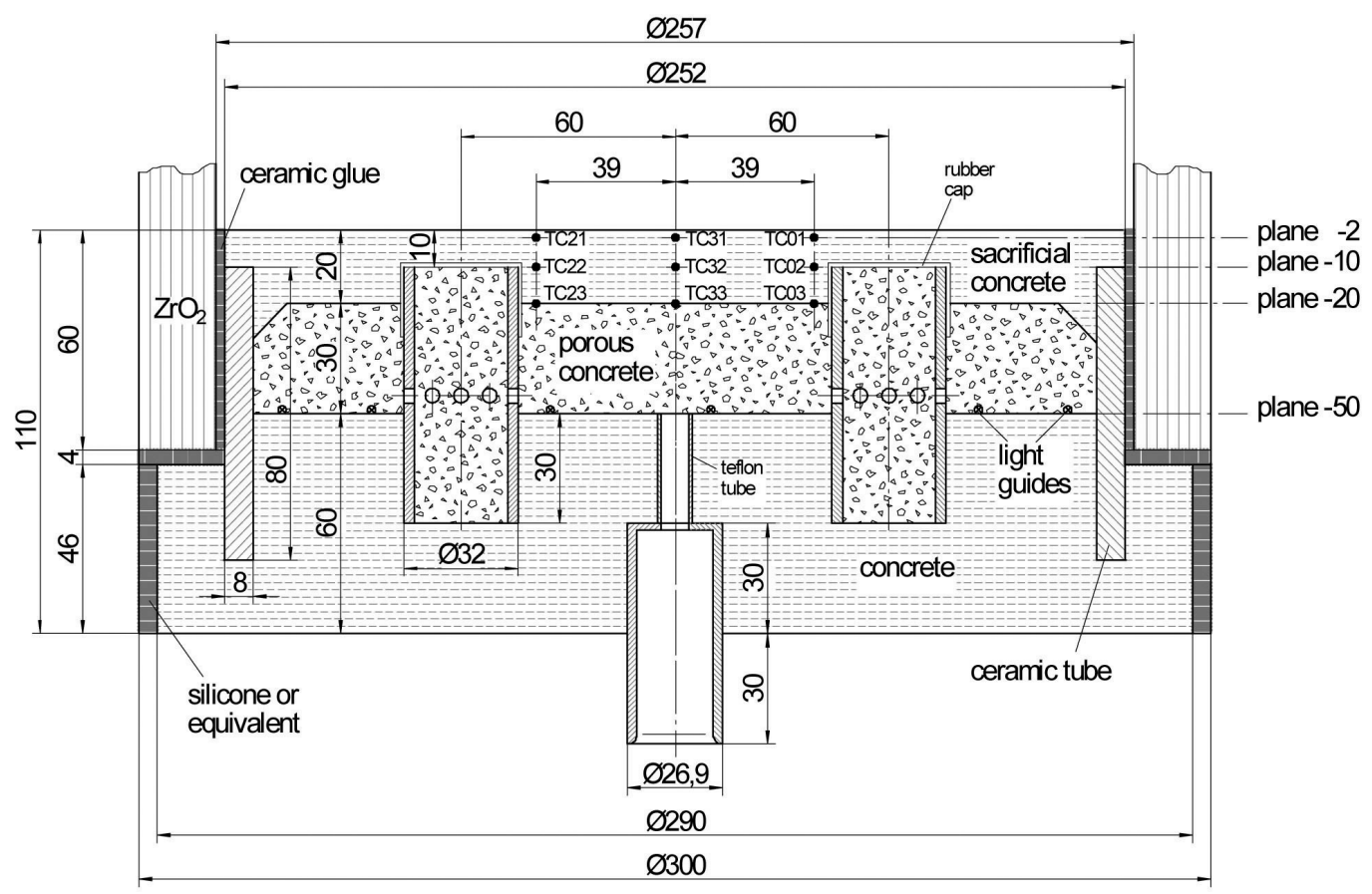

Fig. 11. Sketch of the COMET PCA Corecatcher Installed in the VULCANO VW-U1 Test Section

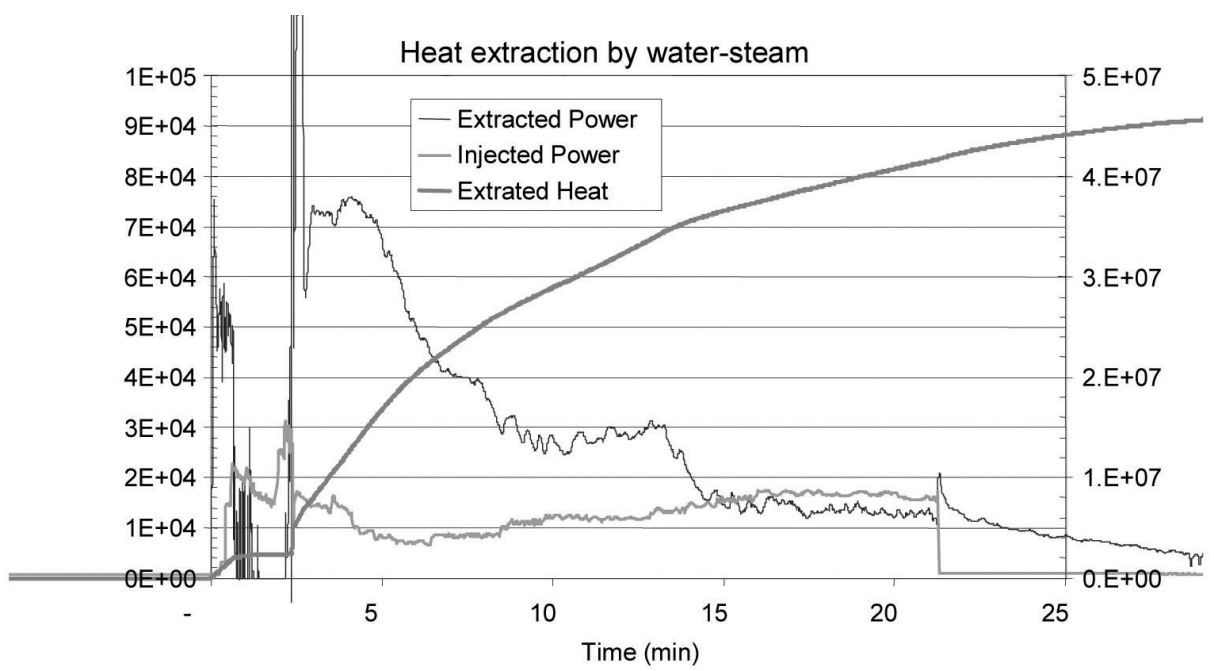

Fig. 12. Heat Generated in the Melt by Induction Heating and Extracted by Evaporation of the Injected Coolant Water.

concrete interaction phase, the bottom flooding passively started leading to efficient heat removal by evaporation form the bulk of the melt. A maximum power of $75 \mathrm{~kW}$ was initially extracted through the generated steam, which was more than 3 times of the injected power, ensuring fast cool-down and solidification of the melt. In the long term, coolability of the corium was characterized by continuous removal of the simulated decay heat.
The temperatures measured at the interface of the porous concrete layer ( 1 centimetre below the water channel outlets) remained around $100^{\circ} \mathrm{C}$ or below. The presence of coolant water in the porous concrete layer keeps the concrete cold, thus providing a safe barrier against the corium that was continuously heated.

The VULCANO VW-U1 test complemented the COMET qualifications tests which had previously been 
carried out at FZK with simulant materials and at ANL with prototypic material but without sustained heating. It shows the great interest of this mitigation system.

\section{CONCLUSIONS}

Twelve Molten Core Concrete Interaction experiments have been carried out with prototypic corium composition with the VULCANO facility. They encompass various aspects of the MCCI issue: ablation by an oxidic melt, ablation by oxides and metal phases and coolability experiments.

Prototypic material experiments are clearly required to analyse corium behaviour due to the coupling of several phenomena that can lead to unexpected results. Whereas spreading prototypic material experiment had proven that this phenomenon was more efficient than previously expected [26] and the VW-U1 test has validated previous simulant material experiments with the COMET concept, at the same time the dry MCCI tests have shown that the phenomenology was more complex than previously expected, launching new research challenges. Nevertheless, empirical models have been developed in the meanwhile which are capable of computing the experimental cases.

The dry oxidic corium tests have contributed to show that silica-rich concretes experience an anisotropic ablation. This unexpected ablation pattern is quite reproducible and can be recalculated, provided an empirical anisotropy factor is assumed. Unfortunately, the phenomenological causes of this anisotropy have not yet been explained even if a large experimental database is now available. At this stage, it is now necessary to conduct more analytic research to complement the result from the global experiments.

Dry tests with oxide and metal liquid phases have also yielded unexpected results: a larger than expected steel oxidation and unexpected topology of the metallic phase (at the bottom of the cavity and also on the vertical concrete walls. Here also, analytical research is needed to understand the causes of the observed phenomena in order to assess their effects at reactor scale.

Finally, VULCANO has proved its interest for the study of mitigation solutions such as the COMET bottom flooding core catcher. The fact that VULCANO can accommodate metallic and oxidic melts and generate heat in the oxides is a unique feature which is necessary to the demonstration of corium coolability.

\section{ACKNOWLEDGEMENTS}

The work and effort of the whole PLINIUS team are gratefully acknowledged.

The VULCANO program has received funding from the European Atomic Energy Community Seventh Framework Programme under grant agreement $n^{\circ} 231747$ (SARNET2), $6^{\text {th }}$ Framework Programme under under contract $\mathrm{n}^{\circ} 036403$ (PLINIUS FP6), $5^{\text {th }}$ Framework
Programme under contract FIR1-CT-2001-40152 (PLINIUS) as well as from a quadripartite agreement between CEA, EDF, IRSN and SUEZ.

\section{REFERENCES}

[1] M. Fischer, The Severe Accident Mitigation Concept and the Design Measures for Core Melt Retention of the European Pressurized Reactor (EPR). Nucl. Eng. Design, 230, 169 (2004).

[2] M. Hirano, T. Yanomoto, M. Ishigaki, N. Watanabe, Y. Maruyama, Y. Shibamoto, T. Watanabe, K. Moriyama, Insights from review and analysis of the Fukushima Daiichi accident, J. Nucl. Sci. Technol.,49, 1 (2012).

[ 3 ] Alsmeyer, H., et al., Molten corium/concrete interaction and corium coolability - a state of the art report. Report EUR 16649, European Commission, Luxembourg (1995).

[ 4 ] B. Schwinges, C. Journeau, T. Haste, L. Meyer, W. Tromm, K. Trambauer, Ranking of severe accident research priorities, Progr. Nucl. Ener., 52, 11 (2010).

[ 5 ] C. Journeau, P. Piluso, Molten Cire Concrete Interaction, In : Comprehensive Nuclear Materials, R.J.M. Konings, ed., vol.2, pp. 635-654, Elsevier, Amsterdam (2012).

[6] C. Journeau, J.M. Bonnet, E. Boccaccio, P. Piluso, J. Monerris, M. Breton, G. Fritz, T. Sevón, P. H. Pankakoski, S. Holmström, J. Virta, European Experiments on 2D Corium-Concrete Interaction: HECLA and VULCANO, Nuclear Technology, 170, 189-200 (2010).

[ 7 ] M.T. Farmer, A Summary of Findings from Melt Coolability and Concrete Interaction (MCCI) Program. Proc. ICAPP'07, Nice, France (2007).

[ 8 ] C. Journeau, P. Piluso, J.F. Haquet, E. Boccaccio, V. Saldo, J.M. Bonnet, S. Malaval, L. Carénini, L. Brissonneau, Twodimensional interaction of oxidic corium with concretes : The VULCANO VB test series, Ann. Nucl. Ener., 36, 1597 (2009).

[9] G. Cognet, G. Laffont, C. Jégou, J. Pierre, C. Journeau, M. Cranga, F. Sudreau, The VULCANO Ex-Vessel Programme. Proc. OECD Wkshp ex-Vessel debris coolability, Karlsruhe, Germany, 156-168 (2000).

[10] C. Jégou, G. Cognet, A. Roubaud, J.M. Gatt, G. Laffont, F. Kassabjo, Plasma transferred arc rotary furnace for corium melting. J. High Temp Mater. Proc., 1, 409 ( 1998).

[11] C. Journeau, L. Ferry, P. Piluso, J. Monerris, M. Breton, G. Fritz, T. Sevon, Two EU-funded VULCANO tests to assess the role of concrete nature on its ablation by molten corium, Proc. ERMSAR 2010, Bologna, Italy (2010).

[12] C. Journeau, J.F. Haquet, B. Letexier, A. Greco, B. Spindler, R. Gencheva, P. groudev, D. Dimov, A. Fargette, J. Foit, B. Michel, C. Mun, T. Sevon, C. Spengler, F. Polidoro, A SARNET Benchmark on two VULCANO Molten Core Concrete Interaction Tests, Proc. ERMSAR 2012, Eur. Rev. Mtg. Severe Accident Res., Cologne, Germany (2012).

[13] C. Journeau, J.F. Haquet, P. Piluso, J.M. Bonnet, Differences between silica and limestone concretes that may affect their interaction with corium, ICAPP'2008, Anaheim, California (2008).

[14] C. Journeau, J.F. Haquet, Convection Heat Transfer Anisotropy in a Bubbling Viscous Pool, Nucl. Eng. Des., 239, 389 (2009).

[15] J.M. Bonnet, Thermalhydraulic phenomena in corium pools for ex-vessel situations: The BALI experiment", Wiss. Ber. 
FZKA, 6475, (2000)

[16] Tourniaire, B., "A heat transfer correlation based on a surface renewal model for molten core concrete interaction study, Nucl. Eng. Des., 236, 10-18 (2006

[17] L. Carenini, J.F. Haquet, C. Journeau, Crust formation and dissolution during corium-concrete interaction, ICAPP'07, Nice, France (2007)

[18] J. Foit, T. Cron, B. Fluhrer, A. Miassoedov, T. Wenz, MOCKA experiment on Concrete Erosion by a Metal and Oxide Melt, $5^{\text {th }}$ European review Meeting on Severe Accident Research, ERMSAR2012, Cologne, Germany (2012).

[19] B. Spindler, B. Tourniaire, J.M. Seiler, Simulation of MCCI with the TOLBIAC-ICB code based on the phase segregation model, Nucl. Eng. Des., 236: 2264 (2006).

[20] B. Spindler, E. Dufour, M. Cranga, D. Dimov, J. Foit, M. Garcia Martin, T. Sevon, W. Schmidt, C. Spengler, Simulation of corium concrete interaction in $2 \mathrm{D}$ geometry : recent benchmarking activities concerning experiemnt and reactor cases, European Review Meeting on Severe Accident Research (ERMSAR-2008), Nessebar, Bulgaria (2008).
[21] B.Tourniaire, J.M. Seiler, J.M. Bonnet, Study of the Mixing of Immiscible Liquids: Results of the BALISE experiments, NURETH-10, Seoul, Korea (2003).

[22] C. Journeau, P. Piluso, J.F. Haquet, S. Saretta, E. Boccaccio, J.M. Bonnet, Oxide-Metal Corium-Concrete Interaction Test in the VULCANO facility, ICAPP'07, Nice, France (2007).

[23] Y. Maruyama, Y., Kojima, M. Tahara, H. Nagasaka, M. Kato, A.A. Kolodeshnikov, V.S. Zhdanov, Yu. S.. Vassiliev, A study on concrete degradation during molten core/concrete interactions. Nucl. Eng. Des., 236, 2237 (2006).

[24] C. Journeau, H. Alsmeyer, Validation of the COMET Bottom-Flloding Core Catcher with Prototypic Corium, ICAPP'06, Reno NV, USA (2006).

[25] W. Tromm, et al., Ex-Vessel Corium Cooling by Passive water Addition through Porous Concrete, Proc. ICONE 9, Nice, France, April 8-12 (2001).

[26] C. Journeau, E. Boccaccio, C. Brayer, G. Cognet, J.F. Haquet, C. Jégou, P. Piluso, J. Monerris, Ex-vessel corium spreading : results from the VULCANO spreading tests, Nucl. Eng. Design, 223: 75 (2003). 